\section{IL-18 und Staphylokokken: „Duo infernale" der atopischen Dermatitis}

\begin{abstract}
Die Produktion von Interleukin 18 in der Epidermis hängt eng mit dem Schweregrad einer atopischer Dermatitis zusammen - besonders bei Patienten, die relativ niedrige IgE-Spiegel aufweisen. Getriggert wird die Synthese durch Staphylococcus-aureus-Kolonien. Diese Erkenntnisse, die von Tierversuchen her bereits bekannt sind, konnte nun auch eine Studie an Patienten und Probanden bestätigen.
\end{abstract}

D en Zusammenhängen, die zwischen atopischer Dermatitis (AD), epidermalem Interleukin 18 (IL-18) und der Hautbesiedlung mit Staphylococcus aureus (S. a.) bestehen, sind Forscher der Yokohama City University in Japan nachgegangen. An ihrer Studie waren 95 Patienten mit $\mathrm{AD}$ und 40 gesunde Kontrollpersonen beteiligt.

Das IL-18 in der Hornschicht der Haut wurde per ELISA bestimmt, nachdem das Material mithilfe eines KlebestreifenAbklatsches in der Ellenbeuge und am Abdomen gewonnen worden war. Außerdem erfassten die Wissenschaftler den klinischen Schweregrad der Hauterkrankung, diverse Blutparameter einschließlich IgE sowie die Kolonisation mit S.a.

Die Konzentrationen von IL-18 in der Hornschicht korrelierten mit dem Haut- befund an den Entnahmestellen und dem allgemeinen Schweregrad der AD, gemessen mit dem SCORAD-Index. Die Behandlung mit topischen Steroiden plus Antihistaminika senkte die IL-18-Spiegel. Im Schnitt hatte das IL-18 in der Ellenbeuge vor der Therapie bei 3,83 pg/ $\mu$ g gelegen; danach wurden Werte von durchschnitt-

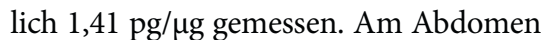
betrugen die entsprechenden Konzentra-

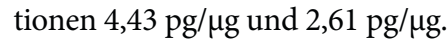

Mehr als $60 \%$ der AD-Patienten, aber nur rund 20\% der gesunden Kontrollpersonen wiesen an den Entnahmestellen Staphylokokken auf. Der S.a.-Nachweis ging jeweils mit signifikant höheren IL18-Spiegeln einher.

Laut den Studienautoren liegt daher die Vermutung nahe, dass S.a. die IL-18Produktion unterstützt. In Tierversuchen war es tatsächlich gelungen, durch Auftragen von S. a.-Protein die IL-18-Synthese in Keratinozyten zu stimulieren. IL-18 seinerseits wirkt direkt auf Mastzellen und Basophile, zudem fördert es die Produktion der Zytokine IL-4 und IL-13 sowie von Histamin.

Bei AD-Patienten mit niedrigen IgESpiegeln im Serum $(<1.500 \mathrm{IU} / \mathrm{ml})$ führte die Kolonisation mit S.a. zu signifikant höheren IL-18-Konzentrationen in der Hornschicht als bei S.a.-freien Patienten. Lagen die IgE-Spiegel höher, war dieser Effekt nicht zu beobachten.

Fazit: Die Besiedlung der Haut mit Staphylococcus aureus kann die epidermale IL-18-Produktion steigern, vor allem bei solchen Patienten, deren atopische Dermatitis mit relativ niedrigen IgE-Spiegeln einhergeht. Therapien, die IL-18 ins Visier nehmen, könnten AD-Patienten daher nützen. Ob dieses Konzept aufgeht, müssen künftige Studien klären.

Dr. Robert Bublak

Inoue $Y$ et al. Interleukin-18 is elevated in the horny layer in patients with atopic dermatitis and is associated with Staphylococcus aureus colonization. Br J Dermatol 2011; 164: 560-7

\section{Beim Haareschneiden lieber geschlossene Schuhe tragen}

Eine Friseurin stellte sich mit einem interdigital lokalisierten Pilonidalsinus am Fuß vor. Sie trug häufig vorne offene Schuhe, wodurch frisch geschnittene Haare auf den Fuß fallen konnten. Durch die Reibung unter der Sandale drangen Haare in die Haut ein und setzten den Krankheitsprozess in Gang.
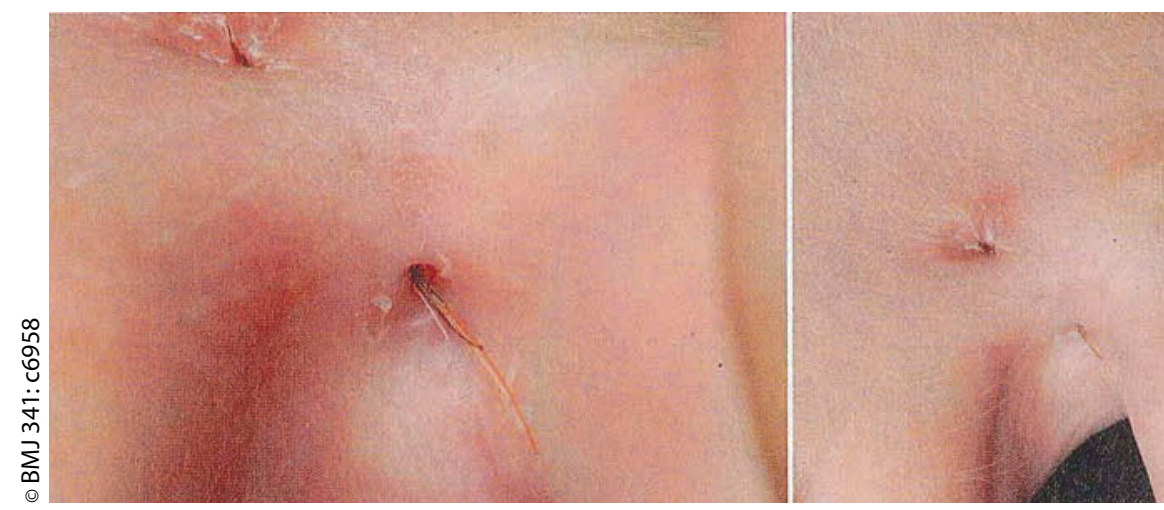

Sinus pilonidalis am Fuß bei einer Friseurin.
A us der Öffnung des Sinus pilonidalis ragten blonde, rote, braune und graue Haare von verschiedenen Kunden (siehe Abb.). Interdigital lokalisierte Sinus pilonidalis sind eine Berufserkrankung, die bei Friseuren üblicherweise nur an der Hand auftrittt. Nur wenige Fälle sind bekannt, bei denen sich die Erkrankung, so wie hier, auch am Fuß manifestierte.

Fazit: Der Befund sieht auf den ersten Blick harmlos aus, die Behandlung ist jedoch langwierig und invasiv. Der betroffene Hautbezirk muss tief und umfangreich exzidiert und die Wunde lange Zeit offen behandelt werden. Daher empfiehlt es sich für Friseure, den Hautkontakt mit frisch geschnittenem Haar möglichst zu meiden.

Prof. Dr. Hermann FüeßI 